\title{
Medicine in the elderly
}

\section{Postural hypotension and falls}

\author{
T Kwok, J Liddle, IR Hastie
}

\section{Falls}

Falls are the most common cause of accidents in older people. ${ }^{1}$ Accidents at home account for $37 \%$ of fatal accidents and of these $57 \%$ occur in people of 75 years and above. ${ }^{2}$ In the Health of the Nation, the Government propose a target reduction of $33 \%$ for fatal accidents in the elderly by the year 2005 . The medical workload from accidents and the numbers of unreported accidents in older people are much higher than previously recognised. ${ }^{3}$ Although the proportion of falls which result in a serious injury is low, the absolute number of older people who suffer fractures is high, and places a heavy demand on both the health and social services. Even falls which result in only minimal physical injury can have significant psychological and social consequences.

Older people fall for many reasons and often with disastrous consequences; a serious injury may signal the end of that older person's independent lifestyle. Illnesses, impairment of the special senses, adverse reactions to drugs and environmental hazards may all contribute. These causes require thorough and skilled detection and assessment followed by proper treatment and preventive measures. In one study, $51 \%$ of falls in women over 65 years were associated with environmental factors and the frequency of intrinsic factors increased from $13 \%$ in women aged 65-69 years to $43 \%$ in those over 85 years. ${ }^{4}$ Studies have demonstrated that the main intrinsic factors are poor balance and muscular weakness. ${ }^{5}$ Muscular weakness in the elderly can be improved by a physical education programme which has also been shown to help balance. ${ }^{6}$

Trials that have looked at the effect of health promotion on the incidence of fractures and accidents in the elderly have produced conflicting results. A study from Oregon randomly selected an intervention group of elderly people who were advised on the removal of hazards from their own homes and given education on health at four group sessions, including advice on exercise, diet, drug safety, and fall prevention. ${ }^{7}$ A reduction of falls and hospitalisation rates were seen in the intervention group. In contrast, a study from Cardiff has shown no effect on fracture rates in an elderly general practice population with a risk of accidents who were targeted for health education, treatment of medical conditions and removal of environmental hazards. ${ }^{8}$ The authors suggest that the health visitors carrying out the study may have increased the risks of accidents by encouraging the elderly, frail, people to be more active. These studies probably show that health intervention has an effect but that current interventions are too little and too late. ${ }^{9}$ The younger elderly need to be encouraged to exercise more and have greater awareness of environmental hazards. More use could be made of existing hazard lists. ${ }^{10}$

A study from the Age Concern Institute of Gerontology, King's College, London investigated existing practice and promising innovations of assessment and management in six metropolitan districts in England. ${ }^{7}$ Consultants, senior nurses and other health care workers in the Accident and Emergency (A\&E) department of each district and in the corresponding geriatric unit were interviewed. A\&E staff perceived access to geriatric assessment in casualty to be a significant problem, and direct admission to geriatric beds to be a major problem in four districts. In two hospitals, there was a reluctance to use short-stay observation beds for elderly patients in case the beds became 'blocked'. In one unit with an integrated admissions policy for acute medical and geriatric patients, ambiguity existed over responsibility for non-medically acute elderly fallers. Geriatricians did recognise that perceived problems of access led to low rates of referral from $A \& E$ departments. The study identified a number of problems for elderly fallers: A\&E departments concentrate on the treatment of injuries rather than establishing the cause of the fall; discharge planning is inadequate due to pressure of work; criteria for referral to geriatric departments is vague and follow-up and monitoring of elderly fallers after discharge from $A \& E$ is lacking. The report recommends greater involvement by geriatricians in A\&E departments, the separate categorisation of 'falls' as a diagnostic group and the introduction of standard assessment procedures with increased use of short-stay 
assessment beds attached to casualty departments. Every district should have a protocol for dealing with elderly people who fall.

\section{Postural hypotension in older people}

Postural hypotension is present if there is a drop in systolic blood pressure of $20 \mathrm{mmHg}$ or more from the supine to the standing position. Its prevalence ranges from $6 \%$ to $24 \%{ }^{11-13}$ depending on the study population and the way the blood pressures are taken. It is positively correlated with supine systolic blood pressure, age, and inversely correlated with body mass index.$^{14,15}$ Standing blood pressure is most commonly taken at one minute after standing and postural hypotension can normally be detected at that time in the symptomatic patients. ${ }^{16}$ Two or three minutes after standing has been used in some studies, ${ }^{17,18}$ however, and different people develop postural hypotension at different times. ${ }^{7}$ The clinical significance of asymptomatic postural hypotension is controversial. ${ }^{19-23}$ The diagnosis of postural hypotension should therefore be confined to those with symptoms. ${ }^{24,25}$ When symptoms are present they tend to fall into three groups: falls and mobility problems, mental confusion and cardiac symptoms. ${ }^{26}$

\section{AETIOLOGY}

Apart from fluid balance problems, the commonest cause of postural hypotension is autonomic failure. In older people, drugs are an important cause of sympathetic dysfunction. Antihypertensives, anticolinergics, phenothiazines and benzodiazepines are the common offenders. Diabetes mellitus is a cause of autonomic dysfunction in all age groups. Dopamine $\beta$-hydroxylase deficiency is an important cause of postural hypotension as it is readily treatable with the precursor drug, L-dihydroxyphenylserine. It was thought to be a genetic disorder but recently an 80-year-old woman was reported to have the condition who had been symptom-free until the age of 60 years. ${ }^{27}$

When postural hypotension is associated with neurological signs (parkinsonian, cerebellar, pyramidal), Shy-Drager syndrome and multiple system atrophy have been described. The autonomic failure is thought to be central in origin, and the prognosis of such patients is poor, most being dead at 5-7 years. ${ }^{28}$ There remains a group of older people who suffer from chronic and often disabling postural hypotension, without any neurological deficit. This is classified as pure or peripheral autonomic failure. It has been suggested that there is end-organ failure of peripheral blood vessels at a precapillary level. ${ }^{29}$

\section{INVESTIGATION}

Investigations can be helpful in confirming the diagnosis of postural hypotension, and to determine the site and extent of the sympathetic dysfunction. The most useful investigation is the head tilt test: the subjects rest supine on an electrically driven tilt-bed with foot support for a set period of time to achieve cardiovascular stability. They are then passively head tilted to $45^{\circ}$ or $60^{\circ}$, or to standing erect. The heart rate is continuously monitored by electrocardiogram (ECG) and beat-by-beat blood pressures are measured electronically, as with Finapres. ${ }^{30}$ The catecholamine levels when supine and on head tilt are measured. A single supine plasma level of catecholamines can be diagnostic of dopamine $\beta$ hydroxylase deficiency: undetectable noradrenaline and adrenaline levels and raised dopamine level (normally undetectable). ${ }^{27}$

Twenty-four hour ambulatory blood pressure may be helpful in determining factors that can contribute to hypotension: time of day, food and exercise. It can be used to assess supine hypertension and to evaluate the efficacy of therapy. Growth hormone response to an intravenous dose of clonidine can be used to distinguish pure (peripheral) autonomic failure from central autonomic failure (Shy-Drager syndrome, multiple system atrophy). The growth hormone level rises in response to clonidine in the former but not in the latter. ${ }^{31}$

- postural hypotension is present if the systolic blood pressure drops by $20 \mathrm{mmHg}$ or more on standing

- autonomic failure is the commonest cause of acute postural hypotension in older people

- ideally blood pressure should be measured supine, $1-3 \mathrm{~min}$ after standing

- the prevalence of postural hypotension increases with age

- postural hypotension may be part of a more generalised problem

- treatment may be either pharmacological or mechanical

\section{MANAGEMENT}

Management of symptomatic postural hypotension in older people should start with the review of medication. Information and advice on life styles which influence blood pressure can be helpful. Postural hypotension is usually more severe in the morning, mainly because of nocturnal recumbent polyuria. ${ }^{32}$ Food ingestion often aggravates postural hypotension..$^{33}$ Exposure to a warm environment, straining during micturition and defaecation, and alcohol are other aggravating factors. Patients with autonomic failure are very sensitive to changes in plasma volume and have an impaired ability to conserve sodium. ${ }^{34}$ They should therefore be encouraged to maintain hydration and have an adequate sodium intake. A head-up tilt at night is probably the most useful nonpharmacological intervention. ${ }^{35}$ It reduces overnight fluid loss and hence 
increases blood volume. Caffeine with meals may attenuate postprandial hypotension ${ }^{36}$ but tolerance may occur. ${ }^{37}$ Physical manoeuvres such as squatting, leg crossing, placing a foot on a chair, and bending forward, if practicable, can alleviate symptoms. ${ }^{38}$

Drug treatment of symptomatic postural hypotension is difficult and the responses vary markedly between patients. The evaluation of drug trials has been hampered by small sample sizes and imprecise diagnosis. Fludrocortisone remains the drug of choice; $0.1 \mathrm{mg}$ at night leads to effective vasoconstriction on standing without aggravating supine hypertension. Higher doses expand plasma volume and necessitate closer observation. ${ }^{35}$ Postaglandin synthetase inhibitors (eg, indomethacin) may be beneficial in some patients ${ }^{39}$ and may be added to fludrocortisone. Nasal desmopressin at night prevents nocturnal polyuria and morning hypotension which are common in people with autonomic failure..$^{32}$ Because of the risk of water intoxication, it needs to be started in hospital, and plasma osmolality and sodium concentration need to be closely monitored. Subcutaneous octreotide, a somatostatin inhibitor, may be helpful in postprandial hypotension. ${ }^{40}$

There have been reports of treatment of postural hypotension with many different drugs affecting different parts of the sympathetic system. ${ }^{41}$ They are $\alpha$-adrenoceptor agonists, (eg, midrodrine), ephedrine, clonidine, vasopressors (eg, ergotamine), monoamine oxidase inhibitors, $\beta$-blocking drugs with high intrinsic sympathomimetic activity (eg, pindolol and xamoterol). Their use is limited by unpredictability of response and supine hypertension.

1 Department of Health. On the state of the public health for 1989. Annual report of the Chief Medical Officer of the Department of Health. London: HMSO, 1990; pp 47-50.

2 Department of Trade and Industry. Home and leisure accident research. Eleventh annual report home accident surveillance system: 1987 data. London: DTI, 1989; p 44.

3 Graham H, Firth J. Home accidents in older people: role of primary health care team. $B M F$ 1992; 305: 30-2.

4 Morfitt JM. Falls in older people at home: intrinsic versus environmental factors in causation. Publ Hlth 1983; 97: 115-20.

5 Campbell JA, Borrie MJ, Spears GF. Risk factors for falls in a community-based prospective study of people 70 years and older. $f$ Gerontol 1989; 44: 112-7.

6 McMurdo MET, Burnett L. A trial of exercise in the elderly. Age Aging 1992; 21 (suppl 2): 8. 7 Adams S, Akham J, Glucksman E, Swift C, Tinker A. Falls and elderly people: a study of current professional practice in England and innovations abroad. London: Age Concern Institute of Gerontology, 1991

8 Vetter NJ, Lewis PA, Ford D. Can health visitors prevent fracture in elderly people? $B M \mathcal{F}$ 1992; 304: 888-90.

9 Turnbull CJ. Accidents in the elderly: time for action. Geriatric Med 1993; 23(2): 16-8.

10 Tideiksaar R. Preventing falls: home hazard checklists to help older patients protect themselves. Geriatrics 1986; 41: 26-8.

11 Caird FI, Andrews GR, Kennedy RD. Effect of posture on blood pressure in the elderly. $B M \mathcal{F}$ 1973; 35: 527-30.

12 Mader SL, Josephson KR, Rubenstein LZ. Low prevalence of postural hypotension among community-dwelling elderly. $\Im A M A$ 1987; 258: 1511-4.

13 Aronow WS, Lee NH, Sales FF, Etienne F. Prevalence of postural hypotension in elderly patients in a long-term health facility. $A m \mathcal{F}$ Cardiol 1988; 62: 336.

14 Rutan GH, Hermanson B, Bild DE, Kittner SJ, older adults. ThS. Orthostatic hypotension in Hypertension 1992; 19: 508-19.

15 Burke V, Beilin LJ, German R, et al. Postural fall in blood pressure in the elderly in relation to drug treatment and other lifestyle factors. $Q f$ Med 1992; 84: 583-91.

16 Wieling W, ten Harkel ADJ, van Lieshout JJ. Spectrum of orthostatic disorders: classification Spectrum of orthostatic disorders: classification
based on an analysis of the short-term cirbased on an analysis of the short-term cir-
culatory response upon standing. Clin Sci 1991; 81: $241-8$.
17 Applegate WB, Davis BR, Black HR, Smith WM, Miller ST, Burlando AJ. Prevalence of postural hypotension at baseline in the systolic hypertension in the elderly program (SHEP) cohort. F Am Geriatr Soc 1991; 39: 1057-64.

18 Burke V, Beilin LJ, German R, et al. Postural fall in blood pressure in the elderly in relation to drug treatment and other lifestyle factors. $O F$ Med 1992; 84: 583-91.

19 Tinetti ME, Williams TF, Mayewski R. Fall risk index for elderly patients based on number of chronic disabilities. Am $\mathcal{F}$ Med 1986; 80: of chron.

20 Lipsitz LA, Pluchino FC, Wei JY, Rowe JW Syncope in institutionalized elderly. $\mathcal{f}$ Chronic Syncope in institution
Dis 1986; 39: 619-30.

21 David BR, Langford HG, Blaofox MD, et al. Association of postural changes in systolic blood pressure and mortality in persons with hypertension: the hypertension detection and follow-up program experience. Circulation 1987; 75: 340-6.

22 Ensrud KE, Nevitt MC, Yunis C, Hulley SB, Grimm RH, Cummings SR. Postural hypotension and postural dizziness in elderly women. The study of osteoporotic fractures. Arch Intern Med 1992; 152: 1058-64.

23 Atkins D, Hanusa B, Sefcik T, Kapoor W. Syncope and orthostatic hypotension. $A m \mathcal{F} M e d$ 1991; 91: 179-85.

24 Schatz IJ. Orthostatic hypotension II. Clinical diagnosis, testing and treatment. Arch Intern Med 1984; 144: 1037-41.

25 Thomas JE, Schirger A, Fealey RD, Sheps SG. Orthostatic hypotension. Mayo Clin Proc 1981; 56: 117-25.

26 Craig GM. Clinical presentation of orthostatic hypotension in the elderly. Postgrad Med $\mathcal{F} 1994$; 70: 638-42.

27 Gentric A, Fouilhopux A, Caroff M, Mottier D, Jouquan J. Dopamine B hydroxylase deficiency responsible for severe dysautonomic orthostatic hypotension in an elderly patient. $\mathcal{f}$ Am Geriat Soc 1993; 41: 550-1.

28 Mathias CJ. Sympathetic nervous system disorders in man. Baillieres Clin Endocrinol Metab 1993; 7: 465-90.

29 Lye M, Vargas E, Faragher EB, Davies I, Goddard C. Haemodynamic and neurohumoral responses in elderly patients with postural hypotension. Eur $¥$ Clin Invest 1990; 20: 90-6.

30 Imholz BPM, Wieling W, Langewouters GJ, van Montfrans GA. Continuous finger arterial van Montfrans GA. Continuous finger arterial pressure: utility in the cardiovascular
laboratory. Clin Auton Res 1991; 1: 43-53.
31 Thomaides TN, Chaudhuri KR, Maule S, Watson $L$, Marsden $C D$, Mathias CJ. Growth hormone response to cloinidine in central and peripheral primary autonomic failure. Lance 1992; 340: 263-6.

32 Mathias CJ, Fosbraey P, da Costa DF, Thornley A, Bannister R. Desmopressin reduces nocturnal polyuria, reverses overnight weight loss and improves morning postural hypotension in amproves morning postural hypotension

33 Mathias CJ, Holly E, Armstrong E, Shareef M, Bannister R. The influence of food on postural hypotension in three groups with chronic hypotension in three groups with chronic autonomic failure - clinical and therapeutic
implications. $f$ Neurol Neurosurg Psychiatry implications. $\mathcal{f} N$

34 Wilcox CS, Puritz R, Lightman SL, Bannister $R$, Aminoff MJ. Plasma volume regulation in patients with progressive autonomic failure during changes in salt intake and posture. $\mathcal{F} \mathrm{Lab} \mathrm{Clin}$ Med 1984; 104: 331-9.

35 Bannister R. Treatment of autonomic failure. Curr Opin Neurol Neurosurg 1992; 5: 487-91.

36 Onrot J, Goldberg MR, Biaggioni I, et al. Hemodynamic and humoral effects of caffeine in autonomic failure: therapeutic implications for postprandial hypotension. $N$ Engl f Med 1985; 313: 549-54.

37 Robertson D, Wade, D, Workman R, Woosley RL. Tolerance to the humoral and hemodynamic effects of caffeine in man. $f$ Clin Invest 1981; 67: 1111-7.

38 Wieling W, van Lieshout JJ, van Leeuwen AM. Physical manoevres that reduce postural hypotension in autonomic failure. Clin Auton Res 1993; 3: 57-65.

39 Abate G, Polimeni RM, Cuccurullo F, Duddu $P$, Lenzi S. Effect of indomethacin on postura hypotension in Parkinsonism. BMF 1979; 2: 1466-8.

40 Armstrong E, Mathias CJ. The effects of the somatostatin analogue, Octreotide, on postural hypotension, before and after food ingestion, in primary autonomic failure. Clin Auton Res 1991; 1: $135-40$.

41 Ahmad RAS, Watson RDS. Treatment of postural hypotension. A review. Drugs 1990; 39: 74-85. 